\title{
Methodological considerations in measuring human calcium absorption: relevance to study the effects of inulin-type fructans
}

\author{
Ian J. Griffin* and Steven A. Abrams \\ USDA/ARS Children's Nutrition Research Center, and Section of Neonatology, Department of Pediatrics, Baylor College of Medicine, \\ 1100 Bates Street, Houston, TX 77030, USA
}

\begin{abstract}
During the last 50 years, a variety of methods have been developed to estimate Ca absorption in man. Mass balances were initially used, but these were unable to accurately measure fractional $\mathrm{Ca}$ absorption because they cannot distinguish unabsorbed dietary Ca from endogenous faecal Ca excretion (excretion of previously absorbed Ca back into the gut). A number of isotopic methods have been developed that can measure true fractional Ca absorption, employing radioisotopes, stable isotopes, or both. Different methods involve collection of urine, faecal or plasma samples. Of the currently available methods, the dual isotope tracer method with a timed urine collection is probably the most precise and reliable. It is also relatively straightforward to carry out and avoids the need for a faecal collection. The purpose of the present paper is to discuss the general advantages and disadvantages of the different methods of $\mathrm{Ca}$ absorption. In addition, the limitations the different methods have in examining the possible effects of non-digestible oligosaccharides on Ca absorption will be discussed.
\end{abstract}

Calcium absorption: Stable isotopes: Non-digestible oligosaccharides

Maintenance of good Ca nutrition is vital throughout the life cycle, both to achieve optimum peak bone mineral mass and to reduce subsequent declines in peak bone mineral mass (IOM, 1997). Ca is absorbed by two main mechanisms - an active saturable transcellular process and a passive non-saturable paracellular process (Weaver \& Heaney, 1999). The paracellular process becomes increasingly important as Ca intake increases and the transcellular pathway becomes saturated (Weaver \& Heaney, 1999).

Active transport appears to be calbindin-dependent and in turn dependent on vitamin $\mathrm{D}$ status as $1,25(\mathrm{OH})_{2}$ vitamin $\mathrm{D}$ increases calbindin mRNA transcription. After binding $\mathrm{Ca}^{2+}$ ions at the luminal surface of the enterocytes, calbindin is internalized via endocytosis. Fusion with lysozymes cause a pH-dependent release of $\mathrm{Ca}^{2+}$ ions and calbindin is recycled to the enterocyte luminal membrane. $\mathrm{Ca}^{2+}$ ions are exported across the basolateral surface by an ATP-dependent $\mathrm{Ca}$ pump, an $\mathrm{Na} / \mathrm{Ca}$ exchanger or by endocytosis (Weaver \& Heaney, 1999). Paracellular Ca transport occurs via the enterocyte tight junctions and is increased as the tightness of the junctions falls (Weaver \& Heaney, 1999).

Although most $\mathrm{Ca}$ absorption occurs in the small intestine, about $5 \%$ occurs in the colon (Barger-Lux et al. 1989). Although this contribution is relatively small, it may be particularly important when examining the effect of non-digestible oligosaccharides on $\mathrm{Ca}$ absorption, as we shall discuss later.

In practical terms, Ca behaves as a threshold nutrient (Matkovic \& Heaney, 1992). When Ca intakes are low, an increase in Ca intake leads to significantly higher $\mathrm{Ca}$ absorption. However, at a certain $\mathrm{Ca}$ intake, a threshold is reached and increasing intake further has relatively little effect on total $\mathrm{Ca}$ absorption (Matkovic \& Heaney, 1992).

\section{Carbohydrates and calcium absorption}

In recent years, there has been an increasing understanding of the role of disaccharides, oligosaccharides, soluble fibre and other carbohydrates as enhancers of $\mathrm{Ca}$ absorption. Animal or human studies support a beneficial effect of lactose (Demigné et al. 1989; Brommage et al. 1993; Abrams et al. 2002), lactulose (Brommage et al. 1993; van den Heuvel et al. 1999a; Beynen et al. 2001), mannitol (Fukahori et al. 1998), pectin (Demigné et al. 1989), polydextran (Hara et al. 2000), starches (Demigné et al. 1989), difructose anhydrides (Mitamura et al. 2002), galactooligosaccharides (Chonan \& Watanuki, 1995; Chonan et al. 1995; van den Heuvel et al. 2000) and inulintype fructans (Delzenne et al. 1995; Ohta et al. 1995a, 1999; Coudray et al. 1997; Griffin et al. 2002, 2003; Uenshi et al. 2002) on $\mathrm{Ca}$ absorption. Of these, the most widely studied in man, are the inulin-type fructans and, to a lesser extent, the galactooligosaccharides. However, before considering the human literature, it is first important to review the possible methods by which $\mathrm{Ca}$ absorption can be measured in man.

\section{Methods to measure calcium absorption in man}

Mass balance

The most obvious method to measure $\mathrm{Ca}$ absorption is using a mass balance. All dietary $\mathrm{Ca}$ consumed over a given period is calculated and $\mathrm{Ca}$ losses in the feces and urine over the corresponding period measured. Ca absorption is given by 


$$
\begin{aligned}
\text { Calcium absorption }= & \text { Calcium intake } \\
& - \text { Urinary calcium excretion } \\
& - \text { Faecal calcium. }
\end{aligned}
$$

However, this method has major limitations. Faecal Ca comprises both dietary $\mathrm{Ca}$ that has been unabsorbed, and absorbed $\mathrm{Ca}$ that has been re-secreted back into the gastrointestinal tract (endogenous faecal $\mathrm{Ca}$ excretion). As such, it measures net $\mathrm{Ca}$ balance rather than true fractional $\mathrm{Ca}$ absorption (Heaney, 2001). Although this may be useful in certain circumstances, it is not the optimal method for assessing the effect of oligosaccharides on $\mathrm{Ca}$ absorption. Oligosaccharides are likely to change $\mathrm{Ca}$ absorption but have little if any direct effect on endogenous faecal $\mathrm{Ca}$ absorption. Therefore, measurement of fractional $\mathrm{Ca}$ absorption is much more helpful in understanding the effects of oligosaccharides on $\mathrm{Ca}$ bioavailability.

\section{Faecal isotope balance}

Radioisotopes had been used since 1940s to study Ca metabolism in animals, but it was not until the mid-1950s that they were used in man. The first isotope used was ${ }^{45} \mathrm{Ca}$, which decays by $\beta$-emission. The radioisotope was administered orally and fractional $\mathrm{Ca}$ excretion measured from the appearance of the isotope in faeces over the next several days (Blau et al. 1954; Bronner \& Harris, 1954, 1956). As the dose of radioisotope given was low, absorbed radioisotope made a minor contribution to the exchangeable $\mathrm{Ca}$ pool. Also, as the faecal collection was of relatively short duration, little absorbed radioisotope was excreted in the gut and the confounding effect of re-secretion of previously absorbed isotope (endogenous faecal $\mathrm{Ca}$ excretion) was minimized. The method, therefore, gave a good estimation of fractional $\mathrm{Ca}$ excretion. Due to its relatively long half-life, orally administered ${ }^{45} \mathrm{Ca}$ could be allowed to equilibrate with the rapidly exchangeable $\mathrm{Ca}$ pool and its subsequent excretion could be used to estimate endogenous faecal Ca excretion (Blau et al. 1957). Similar studies could be carried out with intravenously administered ${ }^{45} \mathrm{Ca}$ (Bronner \& Harris, 1956). The main problems of this method were the exposure to radioactivity and the need for a careful faecal collection. Although using the shorter half-life $\gamma$-emitter ${ }^{47} \mathrm{Ca}$ reduced the radiation exposure (Jaworski et al. 1963), a faecal collection was still required.

\section{Serum isotope appearance}

When a $\mathrm{Ca}$ isotope is given orally, its peak absorption can occur as quickly as 15 min later, after which the serum concentration of the isotope declines exponentially (Szymendera et al. 1972). Several investigators have tried to use the plasma appearance of an oral isotope as a measure of Ca absorption. For example, Bhandarkar et al. (1961) used the specific activity of ${ }^{47} \mathrm{Ca} 2 \mathrm{~h}$ after oral dosing as a measure of $\mathrm{Ca}$ absorption, and Jaworski et al. (1963) used the peak specific activity of ${ }^{47} \mathrm{Ca}$ as an index of $\mathrm{Ca}$ absorption and compared it to the faecal balance method. They studied eight healthy adults whose $\mathrm{Ca}$ absorption by faecal isotope balance was between 30.9 and $43.6 \%$; however, the peak specific activity was much more variable ranging from 1.2 to $2.3 \%$ of the oral dose (Jaworski et al. 1963). The authors concluded, 'the plasma radioactivity peak...was not found to be a reliable index of intestinal calcium absorption' (Jaworski et al. 1963). This is not surprising as the peak specific activity depends on a number of factors in addition to the amount of isotope absorbed. Differences exist, for example, in the size of the exchangeable $\mathrm{Ca}$ pool that oral absorbed $\mathrm{Ca}$ is distributed across (presumably largely a reflection of body size) and this would change specific activity, independent of the amount of isotope absorbed. Furthermore, the specific activity at a given timepoint is the integration of Ca entry to that pool (absorption) and clearance from that pool (a combination of excretion and uptake by tissues). As clearance is likely to vary between individuals, a further source of variability is introduced. This factor should vary little from day-to-day, so paired measurements in the same subject may reflect relative changes in $\mathrm{Ca}$ absorption; however, this method does not allow measurement of absolute fractional $\mathrm{Ca}$ absorption. There are a number of methods to try and correct for these between-subject differences in clearance and pool size. Lekkerkerker et al. (1971) used the clearance of an intravenous dose of ${ }^{45} \mathrm{Ca}$ to correct the plasma appearance curve of a subsequent dose of oral ${ }^{45} \mathrm{Ca}$ and estimate true fractional absorption. Szymendera et al. (1972) administered ${ }^{47} \mathrm{Ca}$ orally and ${ }^{45} \mathrm{Ca}$ intravenously and used the plasma appearance of ${ }^{47} \mathrm{Ca}$ to correct the appearance data for ${ }^{45} \mathrm{Ca}$ and estimate true $\mathrm{Ca}$ absorption. This method gave estimates of true $\mathrm{Ca}$ absorption very similar to those obtained simultaneously from faecal isotope balance or the ${ }^{47} \mathrm{Ca}:{ }^{45} \mathrm{Ca}$ equilibrium ratio in urine and plasma (Szymendera et al. 1972).

A much more appealing correction has been described by Heaney \& Recker (1985) initially in adult women. In this method, the serum specific activity of a radioisotope is measured $5 \mathrm{~h}$ after oral dosing and it is corrected for differences in pool size using a body surface area correction. These investigators measured $\mathrm{Ca}$ absorption by the current gold standard, the dual stable isotope method (see later), and correlated this with the specific activity of an oral isotope in plasma $5 \mathrm{~h}$ later. Together, true $\mathrm{Ca}$ absorption (by the dual isotope tracer method) and body surface area explained almost $92 \%$ of the variance in the $5 \mathrm{~h}$ specific activity of the oral Ca isotope. Ca absorption could be accurately estimated by correcting the $5 \mathrm{~h}$ specific activity for differences in body surface area using the equations (Heaney \& Recker, 1985)

$$
\begin{aligned}
\text { Calcium absorption }= & (2.305 \times 5 \mathrm{~h} \text { specific activity }) \\
& +(0.1084 \times \text { body surface } \text { area }) \\
& -0.1735
\end{aligned}
$$

or

$$
\begin{aligned}
& \text { Calcium absorption } \\
& \begin{aligned}
= & (2.305 \times 5 \mathrm{~h} \text { specific activity }) \\
& +\left(0.0220 \times(\text { weight in kilograms })^{0.425}\right) \\
& \left.\times(\text { height in centimetres })^{0.725}\right)-0.1735
\end{aligned}
\end{aligned}
$$

Subsequently, similar work has been carried out to produce similar equations for adult men (Heaney et al. 2002). Although this method has typically been carried out using radioisotope, there are no theoretical reasons why it could not be modified to use stable isotopes. Currently, the method is only validated in adults and it is inappropriate to extend its use beyond that age range, say to children or adolescents, without additional validation studies.

\section{Dual isotope methods}

The dual isotope tracer method is probably the most commonly used method to measure $\mathrm{Ca}$ absorption and it is widely felt to 
be the optimum method (Heaney, 2001). Two different isotopes are administered - one orally and one intravenously. Ca absorption is measured from the relative recovery of the oral and intravenous isotopes in a urine sample (Abrams, 1999). Several versions of this method have been described differing principally in the timing of the urine collection and whether stable isotopes (Hillman et al. 1988; Abrams, 1999), radioisotopes (Griessen et al. 1985) or both (Beck et al. 2003) are used. The method was first described by Bronner (1962) and subsequently by DeGrazia et al. (1965).

In the early description of the method, urine was collected at least $24 \mathrm{~h}$ after isotope administration and was shown to correlate well with faecal isotope balance (DeGrazia et al. 1965). Subsequently, a complete $24 \mathrm{~h}$ urine collection has been preferred (Hillman et al. 1988; Eastell et al. 1989). This method correlates well with the data from faecal balance (Eastell et al. 1989; Abrams et al. 1994) although the variability is less for the dual isotope tracer method than for faecal balance (Abrams et al. 1994). The dual isotope tracer method also correlated well with estimates made by deconvolution analysis (Yergey et al. 1994) and whole body counting (Beck et al. 2003). However, measurement made on a random 'spot' urine sample significantly overestimate $\mathrm{Ca}$ absorption compared to the dual isotope tracer method (Yergey et al. 1994).

This method is easy to carry out, requiring only a single intravenous infusion and a urine collection (Abrams, 1999). It is more precise than other methods with a $\mathrm{CV}$ for repeated measures in the same subject of about $10 \%$, most of which is true biological variation (Heaney et al. 1988). It is less affected by homeostatic control of plasma $\mathrm{Ca}$ concentrations than some other methods (Heaney, 2001) and the use of tracers increases signal to noise ratio and improves precision (Heaney, 2001). It avoids the need for a prolonged faecal collection, is less variable than faecal balance methods and is generally considered the optimum method of measuring Ca absorption (Heaney, 2001).

We have used such methods to measure $\mathrm{Ca}$ absorption across the entire life cycle (Abrams et al. 1994, 1995, 2002; Abrams, 1999; Ames et al. 1999; Griffin et al. 2002, 2003). A stable isotope is given orally with breakfast and a second isotope given by slow intravenous infusion. As soon as isotopes are administered a 24-h urine collection (occasionally longer) is started. Ca absorption is calculated using the equation (Abrams, 1999)

\section{Calcium absorption \\ $=($ Urinary excretion of oral tracer/Dose of oral tracer $) /$ \\ (Urinary excretion of intravenous tracer/ \\ Dose of intravenous tracer).}

\section{Serum calcium appearance}

Several investigators have attempted to estimate $\mathrm{Ca}$ absorption by the increase in serum $\mathrm{Ca}$ after a relatively large $\mathrm{Ca}$ dose. This has all the disadvantages inherent in the serum isotope appearance method. In addition, a relatively large change in serum Ca concentration is required. However, serum $\mathrm{Ca}$ concentration is under homeostatic control and this serves to damp down the changes in serum $\mathrm{Ca}$ and reduce signal to noise ratio (Heaney, 2001). Heaney (2003) compared the $5 \mathrm{~h}$ specific activity method to the serum Ca absorption method and showed that there was a statistically significant correlation between the two. The area under the curve for serum
Ca appearance was calculated for the first 5, 7,9 or $12 \mathrm{~h}$ after the test meal. The correlation between the $5 \mathrm{~h}$ specific activity method and the serum $\mathrm{Ca}$ absorption method was best when the area under the curve for the first $9 \mathrm{~h}$ was used. However, even in that case, the area under the curve explained less than $50 \%$ of the variability in true fractional $\mathrm{Ca}$ absorption (Heaney, 2003). Although this method may be useful for comparing different groups, it is far less precise than other methods. This is partly because the calcaemia that is required to produce leads to homeostatic changes that serve to blunt the risk in total serum $\mathrm{Ca}$. As isotopic methods require a far smaller rise in total serum $\mathrm{Ca}$ in order to produce measurable changes in serum tracer concentration, these homeostatic effects are greatly reduced.

\section{Urine calcium excretion}

This method uses the urinary excretion of $\mathrm{Ca}$ after a large $\mathrm{Ca}$ load as a measure of $\mathrm{Ca}$ absorption. Therefore, it relies on producing calcaemia proportional to the amount of $\mathrm{Ca}$ absorbed and that this then spills over into the urine. As such it has all the limitations of the serum $\mathrm{Ca}$ appearance method, as well as the additional variability introduced by between-subject differences in renal handling of $\mathrm{Ca}$. This method would be expected to be even more variable and less precise than the serum $\mathrm{Ca}$ appearance method (Heaney, 2001).

\section{Special considerations when studying the effects of non- digestible oligosaccharides on calcium absorption}

As mentioned already, oral $\mathrm{Ca}$ is absorbed very rapidly, with maximum absorption occurring within 15-20 min (Szymendera et al. 1972). Once specific activity peaks, it falls exponentially over the next several days (Szymendera et al. 1972). As the amount of $\mathrm{Ca}$ absorbed distally in the gastrointestinal tract is normally small, measuring absorption $5 \mathrm{~h}$ after ingestion of the isotope can produce good estimates of $\mathrm{Ca}$ absorption (Heaney \& Recker, 1985; Heaney et al. 2002). Under normal circumstances less than $5 \%$ of $\mathrm{Ca}$ absorption occurs in the colon (Barger-Lux et al. 1989). This contribution to total Ca absorption will be 'missed' by measurements that occur before the ingested $\mathrm{Ca}$ has reached the colon, as these measurements cannot anticipate what will occur in the colon. Although this error is usually small, it may be very important when studying the effects of non-digestible oligosaccharides on $\mathrm{Ca}$ absorption.

The mechanisms by which non-digestible oligosaccharides affect $\mathrm{Ca}$ absorption are not entirely clear. In human patients with a permanent ileostomy, almost $90 \%$ of ingested inulintype fructans pass through the ileum undigested. Upon entering the large intestine they may be fermented to SCFA (Van Loo et al. 1999) and lower the $\mathrm{pH}$ of the luminal contents (Greger, 1999), increase the amount of $\mathrm{Ca}$ in the soluble phase and so may increase colonic absorption of $\mathrm{Ca}$. An alternative hypothesis is that non-digestible oligosaccharides have an overall trophic effect on the gut that leads to increased $\mathrm{Ca}$ absorption along the length of the gastrointestinal tract (Greger, 1999). A third possibility is that they may have effects on tight junctions leading to increased paracellular absorption (Mineo et al. 2002). A better understanding of the mechanism(s) by which non-digestible oligosaccharides affect $\mathrm{Ca}$ absorption is urgently needed. Until the potential site at which non-digestible oligosaccharides enhance $\mathrm{Ca}$ absorption is known, the use of methods that are capable of including colonic $\mathrm{Ca}$ absorption should be used. 
Experiments in rats tend to support the first hypothesis and have suggested that non-digestible oligosaccharides may increase $\mathrm{Ca}$ absorption most in the distal parts of the gut (Ohta et al. 1995a). Non-digestible oligosaccharides increase the amount of soluble $\mathrm{Ca}$ in the caecal lumen (Younes et al. 1993; Ohta et al. 1995b) and increase caecal Ca absorption (Ohta et al. 1995a). This enhancement of $\mathrm{Ca}$ absorption is lost in rats following a caecectomy (Ohta et al. 1994). Although the rat is a relatively poor model for human mineral absorption, a similar mechanism may occur in man. In order to fully assess the effect of non-digestible oligosaccharides on $\mathrm{Ca}$ absorption, the selected methods should be able to 'capture' any enhancement of colonic $\mathrm{Ca}$ absorption. The use of methods such as the $5 \mathrm{~h}$ specific activity (Heaney \& Recker, 1985; Heaney et al. 2002) or urine excretion methods carried out a few hours after administration of the test meal would clearly be inadequate for this purpose.

\section{Non-digestible oligosaccharides and Ca absorption}

A number of studies have been carried out on the effect on nondigestible oligosaccharides on $\mathrm{Ca}$ absorption (Table 1). The most studied compounds are the inulin-type fructans such as oligofructose and inulin. The most widely used method has been the dual isotope tracer technique, although mass balances have also been used. More recently, shorter-term urinary methods have been employed (Ohta et al. 1999; Uenshi et al. 2002) that would fail to capture any colonic component to absorption.

A variety of inulin-type fructans have been studied. Oligofructose is a mixture of linear fructans with low degrees of polymerization and short chain length. In contrast, the highmolecular-weight inulins have much longer chain lengths and a higher degree of polymerization. A third type is oligofructoseenriched inulin that contains both short chain length (oligofructose) and long chain length (inulin) fructans. Two studies have been carried out using galactooligosaccharides that like oligofructose have relatively short chain lengths.

van den Heuvel et al. (1998) studied the effect of three different non-digestible oligosaccharides in twelve men using the dual isotope tracer technique. Neither high-molecular-weight inulin, oligofructose nor galactooligosaccharide had any effect on $\mathrm{Ca}$ absorption. These results contradicted earlier work by Coudray et al. (1997) that had shown that high-molecular-weight inulin significantly increased $\mathrm{Ca}$ absorption in adult men using an $8 \mathrm{~d}$ mass balance (Coudray et al. 1997). One possible reason for this discrepancy may have been the length of the urine collection in the van den Heuvel study. It was speculated that the $24 \mathrm{~h}$ collection period used may have been inadequate to capture any enhancing effect of the oligosaccharides on colonic Ca absorption (Coudray \& Fairweather-Tait, 1998). This criticism appeared to be confirmed when further studies by the same investigator showed that both oligofructose (van den Heuvel et al. 1999b) and trans-galactooligosaccharides (van den Heuvel et al. 2000) significantly increased Ca absorption when the dual isotope tracer method was modified to include a $36 \mathrm{~h}$ urine collection. However, since then additional studies have made the effect of oligofructose less, rather than more, clear. Two studies have failed to show any benefit of oligofructose on $\mathrm{Ca}$ absorption using dual isotope tracer methods with a $48 \mathrm{~h}$ urine collection (Griffin et al. 2002) or a 5-7d mass balance (Tahiri et al. 2003). Recently, two studies have shown a beneficial effect of a different type of oligofructose (Meioligo-P; Meiji Seika, Chiyoda, Japan) on Ca absorption (Ohta et al. 1999; Uenshi et al. 2002). However, these studies are methodologically limited as neither could assess the colonic phase of $\mathrm{Ca}$ absorption. Ohta et al. (1999) estimated $\mathrm{Ca}$ absorption from Ca-fortified candies with and without added oligofructose from the urinary excretion of $\mathrm{Ca} 2,4,6$ and $8 \mathrm{~h}$ after ingestion of the candies. At each timepoint, urinary $\mathrm{Ca}$ excretion was highest from the oligofructosecontaining candy (Ohta et al. 1999). These results are difficult to interpret, as the design would have missed any colonic component of $\mathrm{Ca}$ absorption. Furthermore, no adaptation period was allowed before the start of the study. In other studies, variable periods of adaptation have occurred to the oligosaccharide diet. The reason for this is that the proposed mechanism of increased mineral absorption - a change in colonic $\mathrm{pH}$ or an overall trophic effect on the gut - would be expected to take several days to reach a steady state. The results of the Ohta study show, instead, very short-term effects as no adaptation period was allowed (Ohta et al. 1999). This raises the possibility that the addition of oligofructose had a physical effect on the candy leading to increased solubility or bioavailability shortly after consumption. Similar problems exist with the study of Uenshi et al. (2002) who measured Ca absorption from a malt beverage with or without oligofructose.

Table 1. Summary of the studies examining the effects of non-digestible oligosaccharides on calcium absorption in man

\begin{tabular}{|c|c|c|c|c|}
\hline Authors & Oligosaccharide studied & Subjects & Method & Results \\
\hline van den Heuvel et al. (1998) & Oligofructose & 12 men ( $20-30$ years) & Dual isotope ( $24 \mathrm{~h}$ collection) & No change \\
\hline van den Heuvel et al. (1999) & Oligofructose & 12 males ( $14-16$ years) & Dual isotope ( $36 \mathrm{~h}$ collection) & Increase \\
\hline Ohta et al. (1999) & Oligofructose & 10 males & $\begin{array}{l}\text { Urinary } \mathrm{Ca} \\
\qquad(2,4,6,8 \mathrm{~h} \text { samples })\end{array}$ & Increase \\
\hline Griffin et al. (2002) & Oligofructose & 30 girls (11-14 years) & Dual isotope ( $48 \mathrm{~h}$ collection) & No change \\
\hline Uenshi et al. (2002) & Oligofructose & 8 women ( $20-22$ years) & $\begin{array}{l}\text { Urinary } \mathrm{Ca} \text {, urinary } \\
{ }^{44} \mathrm{Ca}:{ }^{43} \mathrm{Ca}(12 \mathrm{~h} \text { collection) }\end{array}$ & Increase \\
\hline Tahiri et al. (2003) & Oligofructose & 12 postmenopausal women & Isotope balance $(5-7 d)$ & No change* \\
\hline Coudray et al. (1997) & $\begin{array}{l}\text { High-molecular- } \\
\text { weight inulin }\end{array}$ & 9 men & Balance $(8 d)$ & Increase \\
\hline van den Heuvel et al. (1998) & $\begin{array}{l}\text { High-molecular- } \\
\text { weight inulin }\end{array}$ & 12 men ( $20-30$ years) & Dual isotope ( $24 \mathrm{~h}$ collection) & No change \\
\hline Griffin et al. (2002) & Oligofructose-enriched inulin & 30 girls (11-14 years) & Dual isotope ( $48 \mathrm{~h}$ collection) & Increase \\
\hline van den Heuvel et al. (1998) & Galactooligosaccharides & 12 men (20-30 years) & Dual isotope ( $24 \mathrm{~h}$ collection) & No change \\
\hline van den Heuvel et al. (2000) & Galactooligosaccharides & 12 postmenopausal women & Dual isotope ( $36 \mathrm{~h}$ collection) & Increase \\
\hline
\end{tabular}

*Trend for increased $\mathrm{Ca}$ absorption in women $>6$ years post-menopause. 
Once again, the method of estimating $\mathrm{Ca}$ absorption (urinary $\mathrm{Ca}$ excretion and urinary ${ }^{43} \mathrm{Ca}:{ }^{44} \mathrm{Ca}$ ratio within $12 \mathrm{~h}$ of taking the drink) would have missed any colonic component and no adaptation period allowed (Uenshi et al. 2002). Once again, this raises the possibility that these inulin-type fructans may be working by a different mechanism than in other studies.

Although the data for short-chain length inulin-type fructans such as oligofructose are contradictory, the data for inulin are more consistent. Except for the study by van den Heuvel et al. (1998) with a $24 \mathrm{~h}$ urine collection discussed earlier, the two other studies using an $8 \mathrm{~d}$ balance (Coudray et al. 1997) or a dual isotope tracer method with $48 \mathrm{~h}$ urine collection (Griffin et al. 2002) show significant effects on $\mathrm{Ca}$ absorption. One of these studies has shown a beneficial effect with a propriety inulin preparation consisting of a combination of high-molecular-weight inulin and oligofructose (i.e. oligofructose-enriched inulin), but not oligofructose alone (Griffin et al. 2002).

There are relatively few data concerning the effect of galactooligosaccharides on Ca absorption. One study by van den Heuvel et al. (1998) using a dual isotope tracer method with a $24 \mathrm{~h}$ urine collection showed no effect on $\mathrm{Ca}$ absorption, while a second study by the same investigators using $36 \mathrm{~h}$ urine collection did show a beneficial effect on Ca absorption (van den Heuvel et al. 2000).

We have recently pooled our data on the effect of oligofructoseenriched inulin on $\mathrm{Ca}$ absorption (Griffin et al. 2002) with investigators from Omaha Nebraska who used a very similar protocol to study the effects of a proprietary oligofructose-enriched inulin (Synergy-1; Orafti, Thienen, Belgium; Griffin et al. 2003). Overall oligofructose-enriched inulin significantly increased $\mathrm{Ca}$ absorption (36.1 (SD 9.8) \% v. 33.1 (SD 9.2)\%, $P=0.027$ ). However, this effect was seen in the Houston cohort (38.2 (SD 9.8) \% v. 32.3 (SD 9.8) $\%, P=0.007$ ) but not in the Omaha cohort (33.9 (SD $8.4) \%$ v. 33.6 (SD 9.4) \%, $P=0.87$ ). Weight, height, age and pubertal stage were not associated with a beneficial response to oligofructose-enriched inulin. The response did differ between different ethnic groups (African-Americans +8.9 (SD 12.2) \%, Caucasians +1.0 (SD 8.4) \%, Hispanics + 13.6 (SD 9.1) \%, Others -1.1 (SD $9.3) \% ; P=0.003)$. The increase in fractional $\mathrm{Ca}$ absorption when consuming oligofructose-enriched inulin was significantly greater in non-Caucasians $(+8.7(\mathrm{SD} 11.0) \%)$ than in Caucasians $(+1.0$ (SD 8.4) \%; $P=0.008)$. When studied by multiple regression analysis, the only factor related to a beneficial effect of oligofructose-enriched inulin was $\mathrm{Ca}$ absorption on placebo. The largest benefit was seen in subjects with the poorest $\mathrm{Ca}$ absorption on placebo. Some of this effect was due to regression to the mean, but a significant proportion was a true biological effect (Griffin et al. 2003). Variability amongst results from different studies may, therefore, be related to intrinsic differences between study populations, as well as differences in methodology and in the exact chemical nature of the oligosaccharides studied. How do the effects of these prebiotics on $\mathrm{Ca}$ absorption compare with other types of fermentable fibre? Is it a fermentation effect or a true prebiotic effect?

\section{Summary and conclusion}

Many methods exist to measure $\mathrm{Ca}$ absorption in man. The preferred method remains the dual isotope tracer method. It is simple to carry out, avoids the need for a prolonged faecal collection and does not involve the use of ionizing radiation. It is also more precise than other methods. In the specific case of non-digestible oligosaccharide, the dual isotope tracer method has a further advantage - the urine collection can be prolonged to capture any colonic component of $\mathrm{Ca}$ absorption.

In order to fully understand the effect of non-digestible oligosaccharides on $\mathrm{Ca}$ absorption, a better understanding of their mechanism of action is required. Do they enhance $\mathrm{Ca}$ absorption along the length of the gastrointestinal tract or selectively increase colonic absorption? To answer this, a more sophisticated approach will be required to examine the kinetics and time course of $\mathrm{Ca}$ absorption before and after adaptation to non-digestible oligosaccharides.

\section{Acknowledgements}

This work is a publication of the US Department of Agriculture (USDA)/Agricultural Research Service (ARS) Children's Nutrition Research Center, Department of Pediatrics, Baylor College of Medicine and Texas Children's Hospital, Houston, TX. This project has been funded in part with federal funds from the USDA/ARS under Cooperative Agreement number 58-6250-6-001, and in part by Orafti, Tienen, Belgium. Contents of this publication do not necessarily reflect the views or policies of the USDA, nor does mention of trade names, commercial products, or organizations imply endorsement by the US Government.

\section{References}

Abrams SA (1999) Using stable isotopes to assess mineral absorption and utilization by children. Am J Clin Nutr 70, 955-964.

Abrams SA, Yergey AL \& Heaney RP (1994) Relationship between balance and dual tracer isotopic measurements of calcium absorption and excretion. J Clin Endocrinol Metab 79, 965-969.

Abrams SA, O'Brien KO, Liang LK \& Stuff JE (1995) Differences in calcium absorption and kinetics between black and white girls aged 5-16 years. J Bone Miner Res 10, 829-833.

Abrams SA, Griffin IJ \& Davila PM (2002) Calcium and zinc absorption from lactose-containing and lactose-free infant formulas. Am J Clin Nutr 76, 442-446.

Ames SK, Ellis KJ, Gunn SK, Copeland KC \& Abrams SA (1999) Vitamin D receptor gene Fok1 polymorphism predicts calcium absorption and bone mineral density in children. J Bone Miner Res 14, 740-746.

Barger-Lux MJ, Heaney RP \& Recker RR (1989) Time course of calcium absorption in humans: evidence for a colonic component. Calcif Tissue Int 44, 308-311.

Beck AB, Bugel S, Sturup S, Jensen M, Molgaard C, Hansen M, Krogsgaard OW \& Sandstrom B (2003) A novel dual radio- and stable-isotope method for measuring calcium absorption in humans: comparison with the whole-body radioisotope retention method. Am J Clin Nutr 77, 399-405.

Beynen AC, Kappert HJ \& Yu S (2001) Dietary lactulose decreases apparent nitrogen absorption and increases apparent calcium and magnesium absorption in healthy dogs. J Anim Physiol Anim Nutr (Berl) 85, $67-72$.

Bhandarkar SD, Bluhm MM, Macgregor J \& Nordin BE (1961) An isotope test of calcium absorption. Br Med J 2, 1539-1541.

Blau M, Spencer H, Swernov J \& Laszlo D (1954) Utilization and intestinal excretion of calcium in man. Science 120, 1029-1031.

Blau M, Spencer H, Swernov J, Greenburg J \& Laszlo D (1957) Effect of intake level on the utilization and intestinal excretion of calcium in man. J Nutr 61, 507-521.

Brommage R, Binacua C, Antille S \& Carrie AL (1993) Intestinal calcium absorption in rats is stimulated by dietary lactulose and other resistant sugars. J Nutr 123, 2186-2194. 
Bronner F (1962) Experimental studies of calcium absorption in man. Nutritio et Dieta 3, 22-31.

Bronner F \& Harris RS (1954) Studies in calcium metabolism. Effect of food phytates on calcium uptake in children on low-calcium breakfasts. J Nutr 54, 523-541.

Bronner F \& Harris RS (1956) Absorption and metabolism of calcium in human beings, studied with calcium-45. Ann NY Acad Sci 64, 314-325.

Chonan O \& Watanuki M (1995) Effect of galactooligosaccharides on calcium absorption in rats. J Nutr Sci Vitaminol (Tokyo) 41, 95-104.

Chonan O, Matsumoto K \& Watanuki M (1995) Effect of galactooligosaccharides on calcium absorption and preventing bone loss in ovariectomized rats. Biosci Biotechnol Biochem 59, 236-239.

Coudray C \& Fairweather-Tait SJ (1998) Do oligosaccharides affect the intestinal absorption of calcium in humans? Am J Clin Nutr 68, 921-923.

Coudray C, Bellanger J, Castiglia-Delavaud C, Rémésy C, Vermorel M \& Rayssignuier Y (1997) Effect of soluble or partly soluble dietary fibres supplementation on absorption and balance of calcium, magnesium, iron and zinc in healthy young men. Eur J Clin Nutr 51, 375-380.

DeGrazia JA, Ivanovich P, Fellows H \& Rich C (1965) A double isotope method for measurement of intestinal absorption of calcium in man. $J$ Lab Clin Med 66, 822-829.

Delzenne N, Aertssens J, Verplaetse H, Roccaro M \& Roberfroid M (1995) Effect of fermentable fructo-oligosaccharides on mineral, nitrogen and energy digestive balance in the rat. Life Sci 57, 1579-1587.

Demigné C, Levrat MA \& Rémésy C (1989) Effects of feeding fermentable carbohydrates on the cecal concentrations of minerals and their fluxes between the cecum and blood plasma in the rat. J Nutr 119, $1625-1630$.

Eastell R, Vieira NE, Yergey AL \& Riggs BL (1989) One-day test using stable isotopes to measure true fractional calcium absorption. $J$ Bone Miner Res 4, 463-468.

Fukahori M, Sakurai H, Akatsu S, Negishi M, Sato H, Goda T \& Takase S (1998) Enhanced absorption of calcium after oral administration of maltitol in the rat intestine. J Pharm Pharmacol, 50, 1227-1232.

Greger JL (1999) Nondigestible carbohydrates and mineral bioavailability. $J$ Nutr 129, 1434S-1435S.

Griessen M, Jung A, Cochet B, Bartholdi P, Gaspoz JM, Infante F, Donath A, Loizeau E \& Courvoisier B (1985) A simple method for measurement of intestinal calcium absorption in humans by double-isotope technique. J Lab Clin Med 105, 641-646.

Griffin IJ, Davila PM \& Abrams SA (2002) The effect of adaptation to moderate dietary intakes of oligosaccharides on calcium absorption in children. Br J Nutr 87, S187-S191.

Griffin IJ, Hicks PD, Heaney RP \& Abrams SA (2003) Enriched chicory inulin increases calcium absorption mainly in girls with lower calcium absorption. Nutr Res 23, 901-909.

Hara H, Suzuki T \& Aoyama Y (2000) Ingestion of the soluble dietary fibre, polydextrose, increases calcium absorption and bone mineralization in normal and total-gastrectomized rats. Br J Nutr 84, 655-661.

Heaney RP (2001) Factors influencing the measurement of bioavailability, taking calcium as a model. $J$ Nutr 131, 1344S-1348S.

Heaney RP (2003) Quantifying human calcium absorption using pharmacokinetic methods. J Nutr 133, 1224-1226.

Heaney RP \& Recker RR (1985) Estimation of true calcium absorption. Ann Intern Med 103, 516-521.

Heaney RP, Recker RR \& Hinders SM (1988) Variability of calcium absorption. Am J Clin Nutr 47, 262-264.

Heaney RP, Dowell MS \& Wolf RL (2002) Estimation of true calcium absorption in men. Clin Chem 48, 786-788.

Hillman LS, Tack E, Covell DG, Vieira NE \& Yergey AL (1988) Measurement of true calcium absorption in premature infants using intravenous ${ }^{46} \mathrm{Ca}$ and oral ${ }^{44} \mathrm{Ca}$. Pediatr Res 23, 589-594.

IOM (1997) Calcium. In Dietary Reference Intervals for Calcium, Phosphorus, Magnesium, Vitamin D and Fluoride, pp. 71-146, Washington DC: National Academy Press.
Jaworski ZF, Brown EM, Fedoruk S \& Seitz H (1963) A method for the study of calcium absorption by the human gut using a standard dose of calcium labeled with Ca-47. N Engl J Med 269, 1103-1111.

Lekkerkerker JF, van Woudenberg F, Beekhuis H \& Doorenbos H (1971) Enhancement of calcium absorption in hypothyroidism. Observations with a new method measuring calcium absorption. Isr J Med Sci 7, $399-400$.

Matkovic V \& Heaney RP (1992) Calcium balance during human growth: evidence for threshold behavior. Am J Clin Nutr 55, 992-996.

Mineo H, Hara H, Shigematsu N, Okuhara Y \& Tomita F (2002) Melibiose, difructose anhydride III and difructose anhydride IV enhance net calcium absorption in rat small and large intestinal epithelium by increasing the passage of tight junctions in vitro. J Nutr 132, 3394-3399.

Mitamura R, Hara H, Aoyama Y \& Chiji H (2002) Supplemental feeding of difructose anhydride III restores calcium absorption impaired by ovariectomy in rats. J Nutr 132, 3387-3393.

Ohta A, Ohtuki M, Takizawa T, Inaba H, Adachi T \& Kimura S (1994) Effects of fructooligosaccharides on the absorption of magnesium and calcium by cecectomized rats. Int J Vitam Nutr Res 64, 316-323.

Ohta A, Ohtsuki M, Baba S, Adachi T, Sakata T \& Sakaguchi E (1995a) Calcium and magnesium absorption from the colon and rectum are increased in rats fed fructooligosaccharides. J Nutr 125, 2417-2424.

Ohta A, Ohtsuki M, Baba S, Takizawa T, Adachi T \& Kimura S (1995b) Effects of fructooligosaccharides on the absorption of iron, calcium and magnesium in iron-deficient anemic rats. J Nutr Sci Vitaminol (Tokyo) 41, 281-291.

Ohta A, Sakai K, Takasaki M \& Tokunga T (1999) Evaluation of the action of calcium resorption enhancement of fructo-oligosaccharides in table candies for humans. Health Nutr Food Res 2.

Szymendera J, Heaney RP \& Saville PD (1972) Intestinal calcium absorption: concurrent use of oral and intravenous tracers and calculation by the inverse convolution method. J Lab Clin Med 79, 570-578.

Tahiri M, Tressol JC, Arnaud J, et al. (2003) Effect of short-chain fructooligosaccharides on intestinal calcium absorption and calcium status in postmenopausal women: a stable-isotope study. Am J Clin Nutr 77, $449-457$.

Uenshi K, Ohta A, Fukushima Y \& Kagawa Y (2002) Effect of a malt drink containing fructooligosaccharides on calcium absorption and safety of long-term administration. Jpn J Nutr Diet 60, 11-18.

van den Heuvel EG, Schaafsma G, Muys T \& van Dokkum W (1998) Nondigestible oligosaccharides do not interfere with calcium and nonheme-iron absorption in young, healthy men. Am J Clin Nutr 67, $445-451$.

van den Heuvel EG, Muijs T, van Dokkum W \& Schaafsma G (1999a) Lactulose stimulates calcium absorption in postmenopausal women. $J$ Bone Miner Res 14, 1211-1216.

van den Heuvel EG, Muys T, van Dokkum W \& Schaafsma G (1999b) Oligofructose stimulates calcium absorption in adolescents. Am J Clin Nutr 69, 544-548.

van den Heuvel EG, Schoterman MH \& Muijs T (2000) Transgalactooligosaccharides stimulate calcium absorption in postmenopausal women. J Nutr 130, 2938-2942.

Van Loo J, Cummings J, Delzenne N, et al. (1999) Functional food properties of non-digestible oligosaccharides: a consensus report from the ENDO project (DGXII AIRII-CT94-1095) [see comments]. Br J Nutr 81, 121-132.

Weaver CM \& Heaney RP (1999) Calcium. In Modern Nutrition in Health and Disease, pp. 141-156 [ME Shils, JA Olson, M Shike and AC Ross, editors]. Baltimore: Williams \& Wilkins.

Yergey AL, Abrams SA, Vieira NE, Aldroubi A, Marini J \& Sidbury JB (1994) Determination of fractional absorption of dietary calcium in humans. J Nutr 124, 674-682.

Younes H, Levrat M, Demigne C \& Rémésy C (1993) Relationship between fermentations and calcium in the cecum of rats fed digestible or resistant starch. Ann Nutr Metab 37, 311-319. 